\title{
PENGUATAN KONSEP KOMPETISI SAINS NASIONAL BAGI GURU DAN SISWA UNGGULAN DI SMAN 7 KOTA LHOKSEUMAWE DAN SMAN 2 DEWANTARA ACEH UTARA: BIDANG KIMIA, FISIKA DAN KEBUMIAN
}

\author{
Mellyzar'), Syafrizal'), Fajrul Wahdi Ginting $^{2)}$ \\ 1)Program Studi Pendidikan Kimia, Fakultas Keguruan dan Ilmu Pendidikan, Universitas Malikussaleh, Aceh Utara, \\ Aceh, Indonesia \\ 2) Program Studi Pendidikan Fisika, Fakultas Keguruan dan Ilmu Pendidikan, Universitas Malikussaleh, Aceh Utara, \\ Aceh, Indonesia \\ Corresponding author : Mellyzar \\ E-mail : mellyzar@unimal.ac.id
}

\section{Diterima 16 November 2021, Disetujui 29 November 2021}

\begin{abstract}
ABSTRAK
Kegiatan pengabdian kepada masyarakat ini bertujuan untuk meningkatkan kompetensi guru dan siswa unggulan untuk menghadapi Kompetisi Sains Nasional (KSN) Tahun 2022. Kegiatan dilaksanakan di SMAN 7 Lhokseumawe dan SMAN 2 Dewantara untuk bidang kimia, fisika dan kebumian. Peserta masing-masing bidang 13 orang, metode pelaksanaannya dengan pembelajaran langsung (direct instruction), latihan dan tanya jawab. Instrumen untuk mengukur tingkat pemahaman peserta dengan menggunakan soal pre-test dan post-test sedangkan untuk mengetahui respon siswa menggunakan kuesioner. Analisis data soal tes dengan menghitung nilai pre-test dan post-test serta nilai N-Gain sedangkan kuesioner dengan persentase. Hasil yang diperoleh dari kegiatan ini terjadi peningkatan pemahaman peserta dengan rata-rata nilai pre-test dan post-test peserta untuk setiap bidang adalah 20 menjadi 60,77 untuk kimia, 13,08 menjadi 56,15 untuk fisika dan 25,38 menjadi 73,08 untuk kebumian. Peningkatan N-Gain tiap peserta dalam kategori tinggi dan sedang. Respon peserta terhadap kegiatan ini juga sangat baik dengan persentase rata-rata kuesioner $82,91 \%$.
\end{abstract}

Kata kunci: kompetisi sains nasional; kimia; fisika; kebumian.

\begin{abstract}
This community service activity aimed to improve the competence of superior teachers and students in facing the National Science Competition (KSN) in 2022. The activities were carried out at SMAN 7 Lhokseumawe and SMAN 2 Dewantara for the fields of chemistry, physics and geoscience. Participants in each field are 13 people, the method of implementation are direct instruction, exercises and questions and answers. Instruments to measure the level of understanding of participants using pre-test and posttest questions while to determine student responses using a questionnaire. Analysis of the test data by calculating the pre-test and post-test scores and the $\mathrm{N}$-Gain value, while the questionnaire used a percentage. Results obtained from this activity increased understanding of the participants with the average value of the pre-test and post-test participants for each field is 20 to 60.77 for chemistry, 13.08 to 56.15 for physics and 25.38 to 73.08 for geoscience. Increased N-Gain of each participant in the high and medium category. Participants' responses to this activity were also very good with an average percentage of $82.91 \%$.
\end{abstract}

Keywords: national science competition; chemical; physics; geoscience.

\section{PENDAHULUAN}

Sejak tahun 2020 Olimpiade Sains Nasional (OSN) berubah nama menjadi Kompetisi Sains Nasional (KSN) setelah Menteri Pendidikan dan Kebudayaan Bapak Nadiem Makarim mendirikan Pusat Prestasi Nasional (Puspresnas) yang menaungi semua kegiatan kompetisi, lomba dan festival di Indonesia. KSN dilaksanakan setiap tahun guna memberi semangat serta daya juang siswa, menjadi jembatan bakat siswa meraih prestasi bidang sains serta kegiatan untuk menyeleksi dan pembinaan peserta untuk berkompetisi pada tingkat internasional (Puspresnas, 2021)

Bidang KSN tingkat SMA terdiri dari sembilan bidang ilmu diantaranya fisika, kimia, matematika, kebumian, astronomi, biologi, informatika/komputer, geografi dan ekonomi. KSN diselenggarakan selain sebagai upaya untuk meningkatkan kompetensi sains, teknologi, dan matematika, kegiatan KSN sebagai upaya menumbuhkan sportivitas, tekun, jujur dan disiplin (Kemdikbud, 2019). 
Sejak tahun 2020, pelaksanaan KSN dilakukan secara daring di rumah. Jika dilaksanakan di sekolah maupun tempat lainnya harus dengan persetujuan Kepala Sekolah dan Satuan Tugas COVID-19 (Ibrahim \& Mumpuni, 2021)

Berdasarkan SK Kepala Puspresnas No.2283/J3/DM.02.00/2021 tentang penetapan pemenang peserta Kompetisi Sains Nasional Tingkat Provinsi (KSN P) Jenjang Sekolah Menengah Atas (SMA/MA) Tahun 2021 untuk Provinsi Aceh ada 14 perwakilan dari 9 bidang kompetisi, jumlah ini tergolong rendah dibandingkan provinsi lainnya di sumatera, berdasarkan SK Kepala Puspresnas jumlah siswa dari provinsi yang ada di sumatera dengan rincian Provinsi Sumatera Utara berhasil mengirim 48 siswa, Riau 35 siswa, Sumatera Barat 27 siswa, Sumatera Selatan 26 siswa, Lampung 22 siswa, Jambi 16 siswa, Kepulauan Riau 13 siswa, Bengkulu 11 siswa dan Bangka Belitung 9 siswa.

Dari 14 siswa yang berasal dari Aceh dengan rincian bidang dan kabupaten asal Aceh berdasarkan hasil KSN P dapat dilihat pada Tabel 1.

Tabel 1. Hasil KSN P SMA/MA Provinsi Aceh

\begin{tabular}{cc}
\hline Bidang KSN & Kabupaten/Kota \\
\hline Astronomi & Banda Aceh \\
Astronomi & Aceh Timur \\
Biologi & Aceh Besar \\
Biologi & Banda Aceh \\
Ekonomi & Banda Aceh \\
Fisika & Aceh Besar \\
Geografi & Aceh Besar \\
Geografi & Aceh Timur \\
Geografi & Lhokseumawe \\
Informatika & Banda Aceh \\
Kebumian & Banda Aceh \\
Kimia & Aceh Selatan \\
Kimia & Aceh Jaya \\
Matematika & Banda Aceh \\
\hline
\end{tabular}

Tabel 1 menunjukkan sebagian besar peserta KSN $P$ Aceh yang berhasil ke tingkat nasional berasal dari Kabupaten/Kota Banda Aceh dengan persentase $42,86 \%$ dari total siswa. Untuk kota Lhokseumawe hanya satu siswa yang berhasil lolos. Tidak ada ada satupun siswa yang berasal dari Aceh Utara yang lolos ketingkat nasional.

Persiapan menghadapi KSN bukan hanya melibatkan siswa saja tanpa dibekali pengetahuan awal dengan bimbingan khusus. KSN memerlukan banyak pihak yang terlibat diantaranya orang tua, guru, sekolah, siswa serta tim khusus untuk mendukung kegiatan ini seperti kerjasama dengan dosen yang pakar dalam bidang kompetisi tersebut (Maulina et al., 2021). Sekolah sangat berperan dalam menyiapkan fasilitas serta melakukan proses seleksi yang baik dan selektif sebagai perwakilan internal untuk menumbuhkan iklim kompetisi yang sehat antar siswa (Muliani et al., 2018). Untuk mendapatkan hasil yang maksimal, pembinaan KSN perlu dilakukan secara intensif yang dapat dilakukan oleh guru dilingkungan sekolah dan perlu juga dilakukan kerjasama dengan dosen atau tenaga ahli untuk meningkatkan kemampuan siswa (Mellyzar, 2021; Harry et al., 2021). Selain siswa guru-guru pembina juga perlu diberikan penguatan materi oleh dosen atau tenaga ahli bidang KSN (Mellyzar et al., 2021).

Universitas Malikussaleh (Unimal) merupakan salah satu universitas negeri di Indonesia yang terletak di Aceh Utara dan Kota Lhokseumawe. Fakultas Keguruan dan IImu Pendidikan (FKIP) Unimal sebagai fakultas yang mencetak guru memiliki tanggung jawab untuk meningkatkan kemampuan siswa dan guru teutama untuk sekolah sekitar kampus. Diperlukan kerjasama Dosen dan Guru dalam menyukseskan kegiatan KSN terutama untuk bidang-bidang tertentu seperti kebumian dan astronomi dikarenakan bidang ini tidak ada pelajaran khusus disekolah (Pranata, 2021).

Hasil observasi awal dan melakukan wawancara tidak terstruktur bersama guru pembina KSN dan kepala SMAN 7 Lhokseumawe dan SMAN 2 Dewantara Aceh Utara diperoleh beberapa permasalahan dalam pembinaan KSN. Pertama; motivasi siswa untuk belajar kurang, menurut guru hal tersebut dipengaruhi oleh lingkungan bermain siswa, keluarga dan kelalaian siswa dalam menggunakan smartphone, siswa mudah menyerah ketika menemukan soal menurut mereka sulit. Kedua; guru juga merasa kesulitan dalam menganalisa dan menjawab soal-soal KSN sehingga dalam pembinaan kurang maksimal, guru hanya memberikan soal-soal yang tingkat kesulitannya rendah. Guru pembina sangat berharap diadakan pelatihan terkait KSN dari analisis soal dan penyelesaiannya.

Dari uraian di atas, permasalahan yang dapat dirumuskan adalah bagaimana dapat menguatkan kompetensi guru dan siswa-siswa unggulan yang menjadi perwakilan sekolah dalam mengikuti KSN dengan pelaksanaan kegiatan ini serta mengetahui respon peserta terhadap kegiatan ini.

Melalui kegiatan Pengabdian Kepada Masyarakat (PkM) Tahun 2021 Dosen FKIP Unimal melakukan kegiatan Penguatan Kompetensi Guru dan Siswa Unggulan SMA Untuk Menghadapi Kompetisi Sains Nasional (KSN) di Lhokseumawe dan Aceh Utara untuk bidang Kimia, Fisika dan Kebumian dengan 
tujuan dapat meningkatkan kompetensi guru dan siswa unggulan di sekolah sekitar kampus Unimal yaitu SMAN 7 Lhokseumawe dan SMAN 2 Dewantara Aceh Utara.

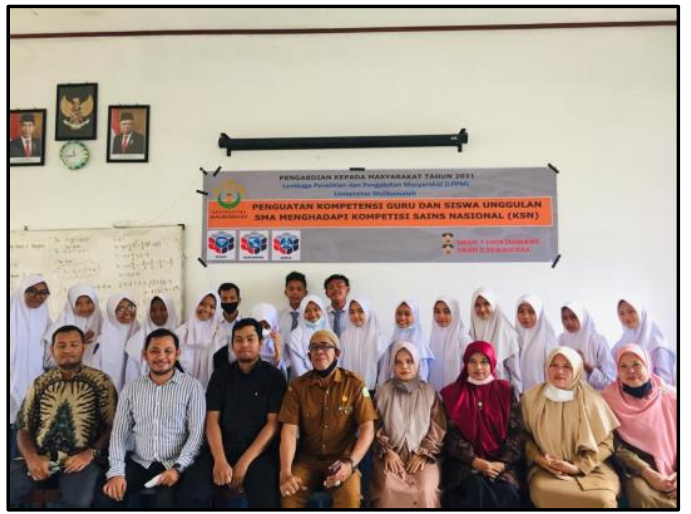

Gambar 1. Foto Bersama Dosen-Guru Pembina dan Siswa SMAN 7 Lhokseumawe

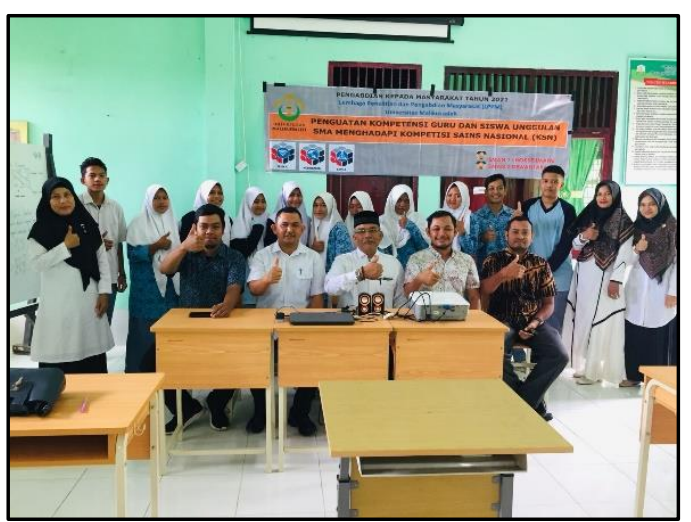

Gambar 2. Foto Bersama Dosen-Guru

Pembina dan Siswa SMAN 2 Dewantara

\section{METODE \\ Tahap Persiapan \\ Analisis situasi}

Analisis awal menggunakan metode survei. Metode survei merupakan cara mengumpul informasi dengan memberi pertanyaan kepada responden individu (Zainal, 2020). Tahap persiapan analisis kebutuhan pelaksanaan PkM diawali dengan melakukan kunjungan dan komunikasi ke SMAN 7 Lhokseumawe dan SMAN 2 Dewantara. Tim PkM melakukan koordinasi dengan kepala sekolah dan guru pembina KSN terkait perizinan, waktu pelaksanaan, kriteria peserta yang ikut dalam kegiatan serta untuk mendapatkan informasi yang berkaitan dengan pelaksanaan bimbingan dan prestasi siswa peserta KSN selama ini. Hasil kegiatan awal ini adalah pihak sekolah mendukung penuh kegiatan, pelaksanaan kegiatan dari $8-13$ November 2021 dengan jumlah peserta masing-masing bidang 13 peserta (11 siswa dan 2 guru) untuk tiap bidang.

\section{Penyusunan bahan ajar dan instrumen} kegiatan

Bahan ajar disiapkan untuk bidang kimia, fisika dan kebumian berupa materi singkat dan soal-soal KSN tahun sebelumnya. Bahan ajar dan soal-soal yang diberikan mengikuti silabus KSN. Instrumen berupa angket, soal pre-test dan post-test. Jenis angket yang digunakan adalah angket respon peserta. Angket diberikan setelah pelaksanaan kegiatan. Soal pre-test dan post-test diadaptasi dari soal KSN tahun sebelumnya.

\section{Tahap Pelaksanaan}

Pelaksanaan kegiatan dimulai dengan memberi motivasi kepada peserta yang disampaikan oleh kepala sekolah dan pengantar dari panitia PkM dan dilanjutkan dengan pelaksanaan pre-test untuk mengetahui kemampuan awal peserta serta kegiatan penguatan kompetensi masing-masing bidang. Metode pengajaran dilaksanakan dengan pembelajaran langsung (direct instruction), latihan dan tanya jawab untuk memberikan pemahaman terkait penguatan konsep dasar materi KSN, pendalaman materi KSN dan pembahasan soal-soal KSN.

\section{Tahap Evaluasi}

Evaluasi kegiatan seminar dilakukan dengan analisis hasil respon peserta terhadap kegiatan serta hasil pre-test dan post-test.

Tabel 2. Kategori Hasil Respon Peserta

\begin{tabular}{cc}
\hline Persentase & Kategori \\
\hline $77,77 \leq X \leq 100$ & Sangat Baik \\
$55,55 \leq X \leq 77,77$ & Baik \\
$33,33 \leq X \leq 55,55$ & Tidak Baik \\
\hline
\end{tabular}

Untuk mengetahui berbedaan kemampuan peserta dalam memahami soalsoal KSN sebelum dan setelah kegiatan kegiatan dengan uji $N$-Gain dengan menggunakan nilai pre-test dan post-tes. Soal pre-test dan post-test yang diberikan dalam kegiatan pembinaan setipe (Bustomi \& Sudarsono, 2021).

Tabel 3. Kategori Nilai N-Gain

\begin{tabular}{cc}
\hline $\mathbf{N}-G a i n$ & Kategori \\
\hline $\mathrm{g} \geq 0,7$ & Tinggi \\
$0,3 \leq \mathrm{g} \leq 0,7$ & Sedang \\
$\mathrm{g} \leq 0,3$ & Rendah \\
\hline
\end{tabular}

\section{HASIL DAN PEMBAHASAN}

Kegiatan pengabdian kepada masyarakat dilaksanakan selama 18 Jam Pelajaran (JP). Jumlah peserta masing-masing bidang sebanyak 13 orang dengan rincian 8 orang tiap bidang dari SMAN 7 Lhokseumawe 
dan 5 orang tiap bidang dari SMAN 2 Dewantara Lhokseumawe. Kegiatan dilakukan secara langsung di kelas dan laboratorium. Materi yang dibahas dalam kegiatan mengikuti silabus KSN dengan rincian seperti pada Tabel 4.

Tabel 4. Rincian Materi Perbidang

\begin{tabular}{|c|c|}
\hline $\begin{array}{l}\text { Bidang } \\
\text { KSN }\end{array}$ & Materi \\
\hline Kimia & $\begin{array}{l}\text { - Konsep dasar kimia (struktur atom, } \\
\text { sistem periodik unsur, ikatan antar } \\
\text { atom, geometri dan bentk molekul, } \\
\text { ikatan antar molekul, delokalisasi } \\
\text { dan resonansi, teori orbital hibrida, } \\
\text { teori orbital molekul) } \\
\text { - Stoikiometri (persamaan reaksi } \\
\text { kimia, perhitugan stoikiometri, } \\
\text { rumus empiris dan rumus } \\
\text { molekul, konsentrasi) } \\
\text { - Kimia Anorganik (Kimia unsur } \\
\text { utama dan transisi) } \\
\text { - Kimia Fisika (kinetika kimia, } \\
\text { termodinamika, kesetimbangan } \\
\text { kimia, sifat koligatif larutan }\end{array}$ \\
\hline Fisika & $\begin{array}{l}\text { - Pengukuran (Besaran dan } \\
\text { satuan, analisa dimensi) } \\
\text { - Kinematika (Gerak lurus, gerak } \\
\text { parabola, gerak melingkar dan } \\
\text { gerak relatif) } \\
\text { - Dinamika Linier (Hukum Newton, } \\
\text { gaya normal, gaya gesek, usaha, } \\
\text { energi dan daya, Energi potensial } \\
\text { dan gaya konservatif, hukum } \\
\text { kekekalan energy, momentum } \\
\text { linear dan impuls, sistem partikel } \\
\text { dan pusat massa, tumbukan dan } \\
\text { hukum kekekalan momentum) } \\
\text { - Dinamika rotasi (momen inersia, } \\
\text { energi kinetik rotasi, torka dan } \\
\text { hukum Newton untuk rotasi, } \\
\text { Kesetimbangan benda tegar, } \\
\text { usaha dan torka, momentum } \\
\text { sudut dan impuls sudut }\end{array}$ \\
\hline $\begin{array}{l}\text { Kebu } \\
\text { an }\end{array}$ & $\begin{array}{l}\text { - Pembetukan bumi } \\
\text { - Struktur internal bumi } \\
\text { - Tektonik lempeng } \\
\text { - Atmosfer meliputi lapisan } \\
\text { atmosfer } \\
\text { - Global warming dan efek rumah } \\
\text { kaca }\end{array}$ \\
\hline
\end{tabular}

Kegiatan penguatan kompetensi guru dan siswa unggulan dalam menghadapi KSN dimulai dengan pre-test yang bertujuan melihat kemampuan awal peserta dan dilanjutkan dengan pelaksanaan bimbingan. Soal pre-test berupa pilihan ganda yang diadaptasi dari soal KSN tahun sebelumnya berjumlah 10 soal.

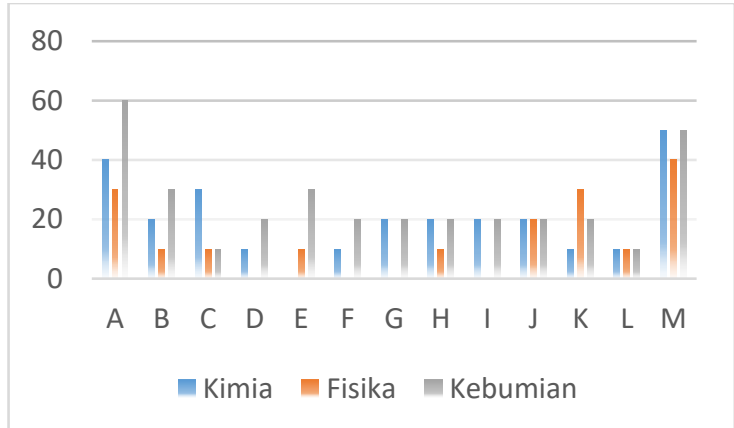

Gambar 3. Hasil Pre-test Peserta

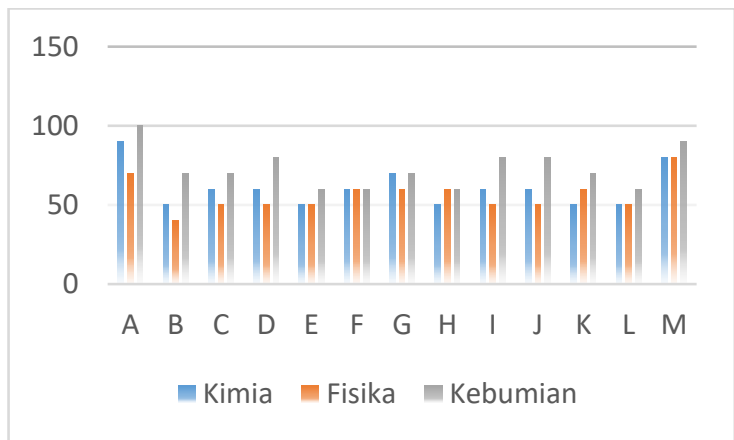

Gambar 4. Hasil Post-test Peserta

Rata-rata nilai pre-test peserta untuk bidang kimia adalah 20 , bidang fisika 13,08 dan bidang kebumian 25,38. Dari nilai rata-rata peserta yang relatif rendah menggambarkan bahwa kemampuan siswa perlu ditingkatkan dalam penguasaan materi standar olimpiade. Rendahnya nilai juga disebabkan siswa sudah terbiasa dengan permasalahan - permasalahan sains yang sederhana dan mudah saja, sehingga siswa tidak mampu menemukan solusi persoalan sains yang rumit (Fitriyah et al., 2019; Suyanto et al., 2020). Untuk nilai post-test peserta terjadi peningkatan dengan rata-rata nilai 60,77 untuk bidang kimia, 56,15 budang fisika dan 73,08 untuk bidang kebumian.

Proses bimbingan pada kegiatan ini dilakukan oleh Mellyzar, M.Pd (Bidang Kimia), Syarizal, M.Si (Bidang Kebumian) dan Fajrul Wahdi Ginting, M.Pd (Bidang Fisika) dengan latar belakang dosen FKIP dan pengajar KSN SMA tingkat Provinsi Aceh.

\section{Bimbingan Bidang Kimia}

Pelaksanaan bimbingan bidang kimia terlaksana sesuai dengan rencana. Pada pertemuan awal kegiatan pembimbing memberi motivasi agar siswa semangat mengikuti rangkaian kegiatan serta trik menghadapi dan melaksanakan kompetisi. Pemaparan materi dimulai dari konsep dasar ilmu kimia dan soalsoal sederhana untuk memicu semangat siswa. 


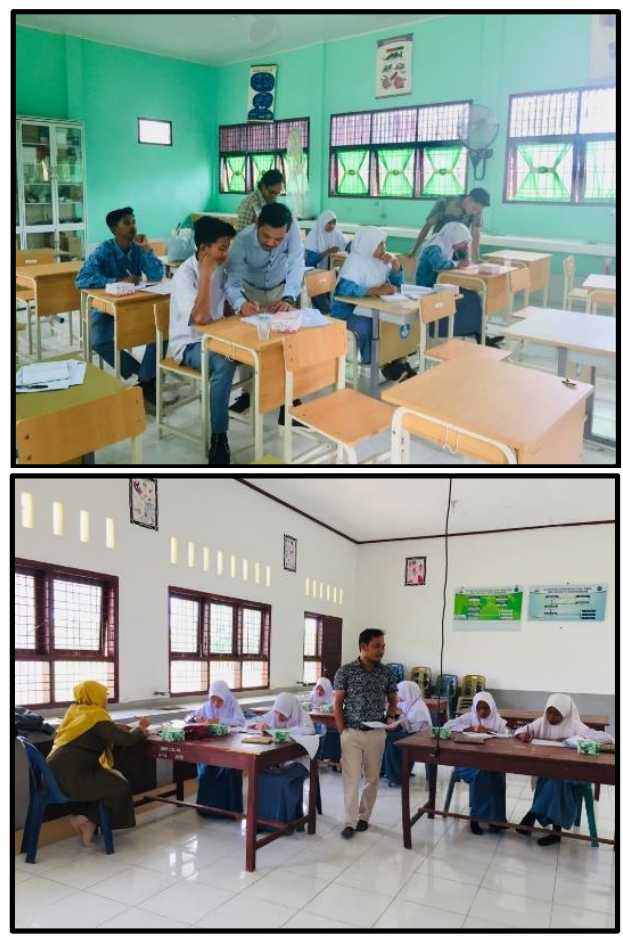

Gambar 5. Bimbingan Bidang Kimia

Kendala awal peserta dalam menyelesaikan soal KSN diantaranya (1) kurang memahami konsep dasar kimia terutama untuk materi struktur atom dan stoikiometri yang merupakan materi dasar dan memiliki hubungan dengan materi-materi lainnya (2) kurang dapat mengoperasi perhitungan matematika dan konversi satuan. Selama proses kegiatan peserta aktif dalam bertanya dan mencoba menyelesaikan soalsoal yang diberikan sebagai latihan dan antusias mengikuti kegiatan dari awal hingga akhir.

Kemampuan peserta bidang kimia mengalami peningkatan, hal tersebut dapat dilihat dari nilai $\mathrm{N}$-Gain hasil pre-test dan posttest peserta pada Tabel 5 .

Tabel 5. Kategori Nilai N-Gain 13 Peserta

\begin{tabular}{ccc}
\multicolumn{3}{c}{ Bidang Kimia } \\
\hline Peserta & N-Gain & Kategori \\
\hline 1 & 0.83 & Tinggi \\
2 & 0.38 & Sedang \\
3 & 0.43 & Sedang \\
4 & 0.56 & Sedang \\
5 & 0.50 & Sedang \\
6 & 0.56 & Sedang \\
7 & 0.63 & Sedang \\
8 & 0.38 & Sedang \\
9 & 0.50 & Sedang \\
10 & 0.50 & Sedang \\
11 & 0.44 & Sedang \\
12 & 0.44 & Sedang \\
13 & 0.60 & Sedang
\end{tabular}

Kegiatan penguatan kompetensi guru dan siswa yang dilaksanakan dapat meningkatkan kemampuan peserta dalam menyelesaikan soal-soal KSN bidang kimia.

\section{Bimbingan Bidang Fisika}

Proses bimbingan bidang fisika berjalan dengan baik. Peserta mengikuti kegiatan dari hari pertama hingga akhir tanpa ada yang absen.

Kendala awal yang dialami peserta terkait soal KSN Fisika adalah kurangnya kemampuan matematika siswa. Kemampuan matematika dasar menjadi komponen penting dalam penguasaan materi fisika (Subekti \& Ariswan, 2016). Selain itu, motivasi siswa masih kurang dalam menyelesaikan soal, ketika membaca soal yang tidak dimengerti siswa cenderung tidak menjawab soal tersebut. Hal tersebut dapat dilihat dari hasil pre-test untuk bidang Fisika memperoleh nilai rata-rata paling rendah dibandingkan bidang Kimia dan Kebumian. Dari 13 peserta yang mengikuti pretest terdapat 4 siswa dengan nilai 0 . Dalam proses pelaksanaan kegiatan pemateri sangat menekankan kepada siswa untuk penguasaan topik pengukuran yang mencakup materi besaran, satuan dan analisis dimensi. Topik ini merupakan dasar dari ilmu fisika dan setiap tahunnya soal-soal terkait topik pengukuran selalu diuji cobakan.

Hasil post-test yang diberikan diakhir kegiatan, mengalami peningkatan dengan ratarata 56,15 . Dari nilai N-Gain yang diperoleh, menjelaskan bahwa peningkatan kemampuan dalam menyelesaikan soal fisika termasuk kategori sedang dengan rincian pada Tabel 6 .

Tabel 6. Kategori Nilai N-Gain 13 Peserta Bidang Fisika

\begin{tabular}{ccc}
\hline Peserta & N-Gain & Kategori \\
\hline 1 & 0.57 & Sedang \\
2 & 0.33 & Sedang \\
3 & 0.44 & Sedang \\
4 & 0.50 & Sedang \\
5 & 0.44 & Sedang \\
6 & 0.60 & Sedang \\
7 & 0.60 & Sedang \\
8 & 0.56 & Sedang \\
9 & 0.50 & Sedang \\
10 & 0.38 & Sedang \\
11 & 0.43 & Sedang \\
12 & 0.44 & Sedang \\
13 & 0.67 & Sedang \\
\hline
\end{tabular}

Kegiatan bimbingan untuk bidang fisika di SMAN 7 Lhokseumawe dan SMAN 2 Dewantara Aceh Utara perlu dilakukan secara intensif dan kontinu baik oleh guru disekolah tersebut ataupun tenaga ahli lainnya serta perlu penguatan materi dasar sebelum membahas 
soal standar KSN. Dari hasil post-test nilai siswa mengalami peningkatan, akan tetapi hanya 2 peserta (1 guru dan 1 siswa) yang memperoleh nilai di atas 50, sedangkan lainnya masih memperoleh nilai $\leq 50$. Soal post-test yang diberikan sama halnya dengan soal pretest dan sebagian besar konsep sudah diberikan selama kegiatan.

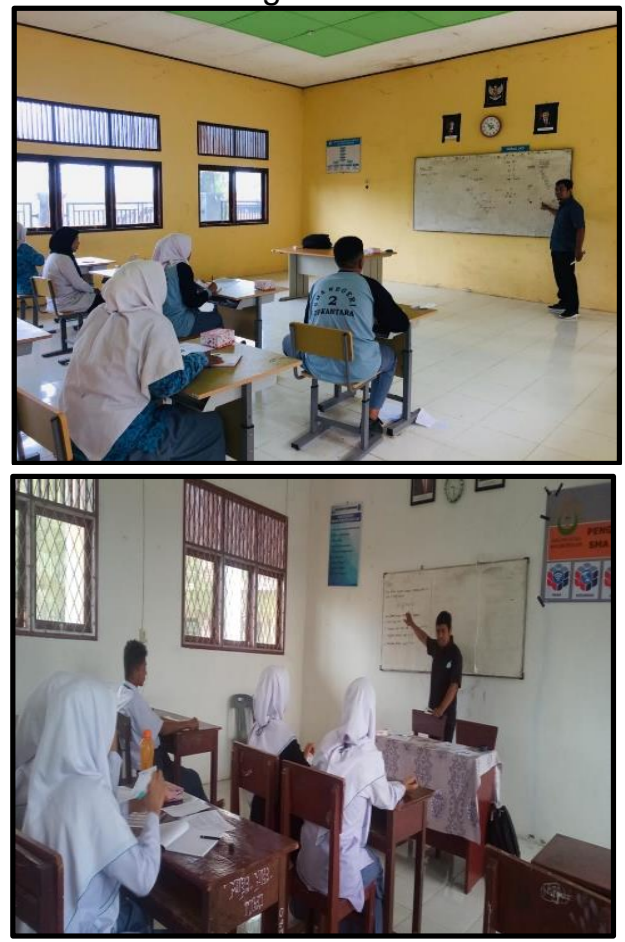

Gambar 6. Bimbingan Bidang Fisika

\section{Bimbingan Bidang Kebumian}

Bidang kebumian merupakan bidang kompetisi yang tidak ada pelajaran khusus di sekolah sepertihalnya kimia dan fisika. Untuk materi bidang kebumian merupakan paduan materi beberapa mata pelajaran seperti fisika, geografi, biologi dan kimia. Guru yang memberi bimbingan untuk bidang kebumian di SMAN 7 Lhokseumawe dan SMAN 2 Dewantara Aceh Utara dengan latar belakang guru bidang Biologi.

Tes awal yang diberikan dengan nilai rata-rata 25,38 dan merupakan nilai yang paling tinggi dibandingkan pre-test bidang kimia dan fisika, bahkan 1 orang siswa mendapat nilai 50 artinya setengah dari soal tes dijawab dengan benar.
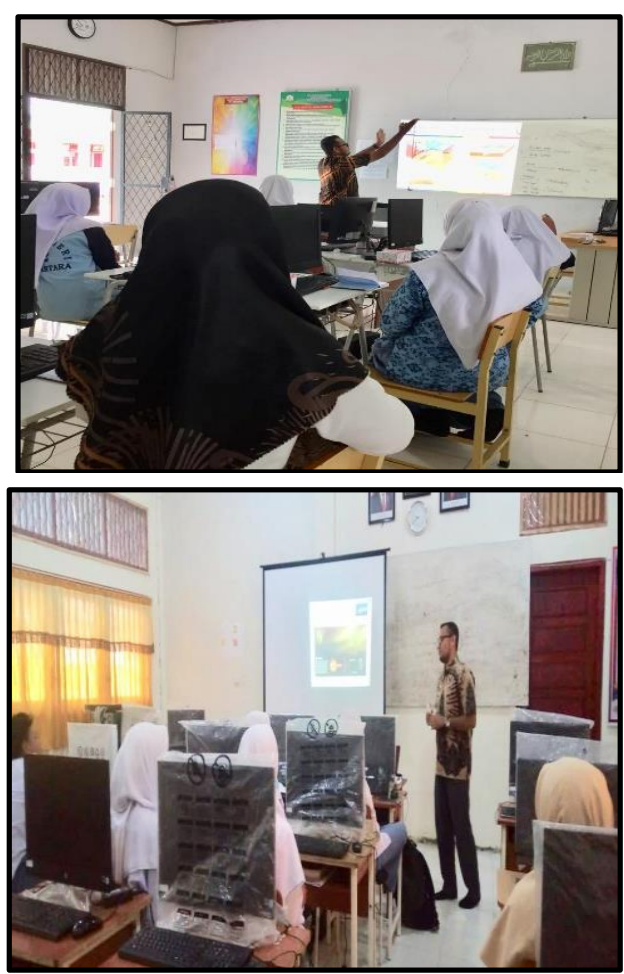

Gambar 7. Bimbingan Bidang Kebumian

Bimbingan bidang kebumian secara umum tidak ada kendala baik dari siswa maupun guru. Informasi yang diperoleh dari Kepala SMAN 2 Dewantara Aceh Utara, pada tahun 2021 ini, siswa sekolah tersebut berhasil memperoleh juara 1 tingkat Kabupaten Aceh Utara (KSN K), hal ini ternyata berpengaruh kepada siswa siswa tingkat bawah dan peminat siswa untuk memilih bidang kebumian juga lebih tinggi dibandingkan bidang lainnya.Ratarata nilai post-test siswa juga sangat baik dengan nilai 73,08. Peningkatan nilai pre-test dan post-test peserta dapat dilihat pada Tabel 7.

Tabel 7. Kategori Nilai N-Gain 13 Peserta Bidang Kebumian

\begin{tabular}{ccc}
\hline Peserta & N-Gain & Kategori \\
\hline 1 & 1.00 & Tinggi \\
2 & 0.57 & Sedang \\
3 & 0.67 & Sedang \\
4 & 0.75 & Tinggi \\
5 & 0.43 & Sedang \\
6 & 0.50 & Sedang \\
7 & 0.63 & Sedang \\
8 & 0.50 & Sedang \\
9 & 0.75 & Tinggi \\
10 & 0.75 & Tinggi \\
11 & 0.63 & Sedang \\
12 & 0.56 & Sedang \\
13 & 0.80 & Tinggi \\
\hline
\end{tabular}


Kuesioner perlu diberikan untuk mengetahui respon peserta terhadap kegiatan yang sudah dilakukan (Styawati et al., 2021). Kuesioner yang diberikan memuat pernyataan untuk menilai 4 aspek yaitu pemahaman materi, motivasi dalam belajar materi $\mathrm{KSN}$, alokasi waktu selama kegiatan, serta penilaian terhadap pemateri. Kuesioner menggunakan 3 pilihan jawaban yaitu Sangat Setuju (SS) Setuju (S) dan Tidak Setuju (TS).

Tabel 8. Respon Peserta Terhadap Kegiatan

\begin{tabular}{lcc}
\hline \multicolumn{1}{c}{ Aspek } & $\%$ & Kategori \\
\hline Pemahaman Materi & 76,92 & Baik \\
Motivasi & 77,78 & Sangat Baik \\
Alokasi Waktu & 74,95 & Baik \\
Performa pemateri & 94,02 & Sangat Baik \\
Keseluruhan & 82,91 & Sangat Baik \\
\hline
\end{tabular}

Dari analisis kuesioner yang diisi peserta, persentase paling tinggi pada aspek performa pemateri. Pada aspek ini, adapun pernyataan yang dinilai terdiri dari 3 pernyataan yaitu (1) pemateri mampu menyampaikan konsep dengan baik dan menarik (2) pemateri mampu menyelesaikan masalah dalam soalsoal KSN dengan baik dan dapat dipahami (3) pemateri mampu memberikan motivasi, saran, strategi untuk mengikuti KSN. Secara keseluruhan respon siswa sangat baik dengan persentase $82,91 \%$. Kegiatan ini dinilai positif dan bermanfaat bagi guru dan siswa dengan harapan dapat meningkatkan jumlah peserta KSN dari sekolah yang akan tembus ketingkat provinsi bahkan nasional. Peserta juga menuliskan saran agar kegaiatan PkM ini dapat dilakukan secara berkelanjutan.

\section{SIMPULAN DAN SARAN}

Simpulan yang diperoleh dari hasil pengabdian ini adalah pemahaman konsep guru dan siswa unggulan terkait KSN mengalami peningkatan untuk setiap bidang. Berdasarkan nilai pre-test dan post-tes peserta rata-rata untuk setiap bidang yaitu bidang kimia nilai 20 menjadi 60,77 , bidang fisika 13,08 menjadi 56,15 dan bidang kebumian 25,38 menjadi 73,08 . Dan peningkatan $\mathrm{N}$-Gain tiap peserta dalam kategori tinggi dan sedang. Respon peserta terhadap kegiatan ini juga sangat baik dengan persentase rata-rata kuesioner $82,91 \%$.

Dari kegiatan pengabdian ini, beberapa saran yang dapat diberikan antara lain (1) bimbingan KSN agar terus rutin dilaksanakan dan terjadwal tidak hanya dilakukan ketika beberapa hari menjelang kompetisi (2) dalam melakukan bimbingan guru harus membiasakan membahas soal KSN tahun terbaru dikarenakan soalnya lebih variatif (3) selalu memberikan motivasi kepada siswa bahwa setiap siswa memiliki kesempatan untuk juara.

\section{UCAPAN TERIMAKASIH}

Ucapan terima kasih kami sampaikan kepada Universitas Malikussaleh dan LPPM Universitas Malikussaleh yang telah memberikan dukungan dan dana pelaksanaan pengabdian yang bersumber dari dana PNBP tahun 2021. Terima kasih juga kepada Kepala SMAN 7 Lhokseumawe dan Kepala SMAN 2 Dewantara Aceh Utara yang telah memberikan kesempatan dan fasilitas untuk pelaksanaan pengabdian ini, beserta seluruh peserta dari Guru pembimbing KSN dan siswa-siswa unggulan peserta KSN 2022 bidang Kimia, Fisika dan Kebumian.

\section{DAFTAR RUJUKAN}

Bustomi, M. A., \& Sudarsono, S. (2021). Pembinaan OSP IPA SMP Sekota Surabaya oleh Departemen Fisika Institut Teknologi Sepuluh Nopember (ITS). Jurnal Altifani Penelitian Dan Pengabdian Kepada Masyarakat, 1(2), 69-76.

Fitriyah, D., Sarkity, D., Elvi, M., \& Liana, M. (2019). Pembinaan Penyelesaian Soalsoal Olimpiade Sains bagi Siswa SMP Negeri 4 Tanjungpinang. Jurnal Anugerah, 1(2), 77-81. https://doi.org/10.31629/anugerah.v1i2.1 826

Harry, S., Prayitno, S., Hamdani, D., Apsari, R. A., \& Wulandari, N. P. (2021). Desain Pembinaan Bakat Matematika siswa SMP untuk Persiapan Menghadapi Kompetisi Sains Nasional. Sasambo: Jurnal Abdimas (Journal of Community Service), 3(1), 32-40.

Ibrahim, I. U., \& Mumpuni, K. (2021). Panduan Pelaksanaan Kompetisi Sains Nasional Tingkat Provinsi 2021. Jakarta: Puspresnas. Puspresnas.

Kemdikbud. (2019). Pengumuman Hasil OSP Tahun 2019.

Maulina, D., Pramudiyanti, P., Rakhmawati, I., \& Meriza, N. (2021). Program Pendampingan Kegiatan Kompetisi Sains Nasional Bidang Biologi Siswa SMAN 5 Bandar Lampung. Wikrama Parahita: Jurnal Pengabdian Masyarakat, 5(1), 7379.

https://doi.org/10.30656/jpmwp.v5i1.2818

Mellyzar, M. (2021). Pendampingan Persiapan Kompetensi Sains Nasional (KSN) Tingkat Provinsi Di SMAN Modal Bangsa Arun Aceh. Humanis, 20(1), 14-16. https://doi.org/doi.org/10.26858/humanis. v20i1.19192

Mellyzar, M., Herizal, H., Ginting, F. W., \& 
Syafrizal, S. (2021). PENGUATAN MATERI KOMPETISI SAINS NASIONAL (KSN) BAGI GURU SMA DI ACEH UTARA. Jurnal Penelitian Dan Pengabdian Kepada Masyarakat UNSIQ, 8(2), 184-188.

Muliani, F., Noviati, D., \& . F. (2018). PEMBINAAN PENINGKATAN MUTU PENDIDIKAN BIDANG OLIMPIADE SAINS BAGI GURU SD KOTA LANGSA PROVINSI ACEH. Jurnal Pengabdian Masyarakat Universitas Merdeka Malang, 3(2), 9-13. https://doi.org/10.26905/abdimas.v3i2.25 86

Pranata, O. D. (2021). Kerjasama Guru-Dosen Untuk Menghadapi Tantangan Besar Dalam Kompetisi Sains Cabang Kebumian. Jurnal Penelitian Dan Pengabdian Kepada Masyarakat UNSIQ, 8(3), 315-321.

Puspresnas. (2021). Panduan Pelaksanaan Kompetisi Sains Nasional Tahun 2021. Pusat Prestasi Nasional Kemdikbut RI.

Styawati, S., Oktaviani, L., \& Lathifah, L. (2021). Penerapan Sistem Pembelajaran Dalam Jaringan Berbasis Web Pada Madrasah Aliyah Negeri 1 Pesawaran. Jurnal Widya Laksmi, 1(2), 68-75.

Subekti, Y., \& Ariswan, A. (2016). Pembelajaran fisika dengan metode eksperimen untuk meningkatkan hasil belajar kognitif dan keterampilan proses sains. Jurnal Inovasi Pendidikan IPA, 2(2), 252. https://doi.org/10.21831/jipi.v2i2.6278

Suyanto, E., Safitri, A., Kurnianingsih, N., \& Fatchiyah, F. (2020). Pendampingan Penguatan Kompetensi Guru dan Siswa SMA Melalui Pengembangan Inovasi Sains dan Kompetisi Olimpiade Biologi di Kabupaten Sampang, Madura. Engagement: Jurnal Pengabdian Kepada Masyarakat, 4(2), 402-424. https://doi.org/10.29062/engagement.v4i2 .288

Zainal, A. (2020). Metodologi penelitian pendidikan. Jurnal Al-Hikmah, 1(1). 